\title{
Short versus standard peroral endoscopic myotomy for esophageal achalasia: a systematic review and meta-analysis
}

\author{
Sami Ghazaleha, Azizullah Berana, Yasmin Khadera, Christian Nehmea, Justin Chuanga, Sachit Sharmaa, \\ Muhammad Aziz ${ }^{b}$, Zubair Khan', Ahmed M. Elzanaty ${ }^{a}$, Jordan Burlen ${ }^{b}$, Ali Nawras ${ }^{b}$
}

University of Toledo, Toledo, OH; University of Texas, Houston, TX, USA

\section{Abstract}

\section{Introduction}

Esophageal achalasia is an uncommon esophageal motility disorder that results from the degeneration of ganglion cells in

\begin{abstract}
${ }^{a}$ Department of Internal Medicine, University of Toledo, Toledo, $\mathrm{OH}$ (Sami Ghazaleh, Azizullah Beran, Yasmin Khader, Christian Nehme, Justin Chuang, Sachit Sharma, Ahmed M. Elzanaty); ${ }^{\text {DDivision of }}$ Gastroenterology and Hepatology, University of Toledo, Toledo, $\mathrm{OH}$ (Muhammad Aziz, Jordan Burlen, Ali Nawras); 'Division of Gastroenterology and Hepatology, University of Texas, Houston, TX (Zubair Khan), USA

Conflict of Interest: None
\end{abstract}

Correspondence to: Sami Ghazaleh, MD, University of Toledo, 2100 West Central Ave, Toledo, OH 43606, USA,

e-mail: sami.ghazaleh@utoledo.edu

Received 12 February 2021; accepted 7 April 2021; published online 14 June 2021

DOI: https://doi.org/10.20524/aog.2021.0644 the esophageal wall. This leads to aperistalsis and incomplete relaxation of the lower esophageal sphincter (LES), which manifests with dysphagia, weight loss, and regurgitation [1]. Treatment of achalasia is aimed at lowering the resting LES pressure, which can be achieved by mechanical disruption of the LES muscles. This can be accomplished by surgical myotomy, pneumatic dilation, or peroral endoscopic myotomy (POEM) [2]. Laparoscopic Heller myotomy (LHM) has been the gold standard for the treatment of achalasia because of its high efficacy and durability. POEM is a newer technique performed endoscopically and does not require incisions in the chest or abdomen [3].

POEM is equivalent to LHM in terms of efficacy in relieving dysphagia in the short term [4]. LHM is usually combined with fundoplication to prevent acid reflex, but POEM includes no antireflux procedure [3,5]. Therefore, POEM is associated with higher rates of postoperative gastroesophageal reflux disease (GERD) by multiple measurements, including reflux symptoms, reflux esophagitis on endoscopy and pathologic acid exposure on $\mathrm{pH}$ monitoring [4]. Recently, a few studies have suggested that a modified POEM with a shorter myotomy 
length could reduce the incidence of postoperative GERD while achieving the same clinical success rate [6].

The literature lacks high-quality evidence that compares the clinical outcomes of short and standard POEM for esophageal achalasia. The purpose of our systematic review and metaanalysis was to compare short and standard POEM in terms of clinical success and to determine whether a shorter myotomy could reduce the incidence of postoperative GERD.

\section{Materials and methods}

\section{Data sources and search strategy}

The meta-analysis protocol was registered on PROSPERO (ID: CRD42020222752). We performed a comprehensive search for studies that compared short and standard POEM for esophageal achalasia. We searched the databases of PubMed/MEDLINE, Embase, the Cochrane Central Register of Controlled Trials, and Web of Science Core Collection. The following were the main search terms: ("peroral endoscopic myotomy" or "POEM") and ("short" or "shorter") and "achalasia". Supplementary Table 1 describes the search strategy used in our electronic search. We included all publications that fit our search from inception until October 30, 2020, not limited by language, study design or country of origin. We also included relevant studies using references of eligible publications. We tried to obtain the full texts of all potential studies including contact with the authors.

\section{Study selection}

We followed the preferred reporting items for systematic reviews and meta-analyses (PRISMA) and the meta-analysis of observational studies in epidemiology (MOOSE) guidelines to screen the studies $[7,8]$. Two researchers (SG and $A B$ ) independently screened and selected the studies for the final review. Discrepancies were resolved by a third researcher (YK). We considered full texts and abstracts of randomized controlled trials (RCTs), cohort studies, case-control studies and case series. We excluded single-arm studies, animal studies, case reports, case series with a sample size $<10$ patients, reviews, editorials, and letters to the Editor. We also excluded preprints if the peer review process was not complete.

\section{Data extraction}

We extracted the following data from the final studies: last name of first author, publication date, country of origin, study design, study period, follow-up duration, sex, age, and sample size. We also extracted the number of patients who underwent short or standard POEM and their preoperative characteristics, including Eckardt score, basal LES pressure, 4 -sec integrated relaxation pressure (4sIRP), and barium column diameter. Finally, we extracted relevant perioperative details, including myotomy length, operation time, length of hospital stay, and perioperative complications. Institutional review board approval and written consent was not needed for this paper.

\section{Outcomes}

The primary outcome of our meta-analysis was the clinical success of POEM, which was defined as a postoperative Eckardt score of 3 or lower. Secondary outcomes were postoperative Eckardt score, change in Eckardt score, postoperative basal LES pressure, postoperative 4sIRP, and postoperative barium column diameter. We also extracted outcomes related to the occurrence of postoperative GERD, including reflux symptoms, reflux esophagitis on endoscopy, and pathologic acid exposure on $\mathrm{pH}$ monitoring.

\section{Statistical analysis}

The meta-analysis was performed using Review Manager 5.4 (Cochrane Collaboration, Copenhagen, The Nordic Cochrane Centre) and Comprehensive MetaAnalysis (Biostat, Englewood, USA). A random-effects model was used to calculate the weighted pooled risk ratios (RR), mean differences (MD), and 95\% confidence intervals (CI) of our desired outcomes. We planned for subgroup analysis according to clinical success, based on publication status (abstract vs. publication) and study design (RCT vs. retrospective cohort). We also planned for subgroup analysis according to reflux esophagitis, based on depth of myotomy (circular myotomy vs. circular myotomy in the upper part of the tunnel and full thickness in the lower part). A P-value $<0.05$ was considered statistically significant. Heterogeneity was assessed using the Higgins $I^{2}$ index, where $I^{2}$ values $>50 \%$ implied the presence of substantial heterogeneity [9].

\section{Quality and publication bias assessment}

The quality of the included studies was assessed using the revised Cochrane risk of bias tool ( $R o B$ 2) for RCTs, and the Newcastle-Ottawa scale for cohort studies [10,11]. Publication bias was assessed visually by generating a funnel plot of the studies that reported the clinical success rate.

\section{Results}

\section{Study selection}

A total of 570 studies were retrieved by our search strategy. We removed 231 duplicate studies and reviewed the remaining 
339. We excluded 331 studies based on the titles and abstracts and reviewed the full texts of the remaining 8 studies. Finally, 5 studies met our inclusion and exclusion criteria [12-16]. Fig. 1 shows the PRISMA flow chart that illustrates how the final studies were selected.

\section{Study characteristics}

Table 1 shows the characteristics of the 5 studies included in our meta-analysis. The studies included 474 esophageal achalasia patients who underwent POEM, of whom 214 underwent short myotomy and 260 standard myotomy. The studies were published between April 2016 and October 2020. Three studies originated from China, 1 from Italy, and 1 from India. As regards design, 3 studies were RCTs and 2 were retrospective cohorts. Of the included studies, 4 were full-text publications and 1 was an abstract. The mean age was 42.5 years and males represented $49.6 \%$ of the total participants. Supplementary Table 2 summarizes the preoperative, perioperative, and postoperative outcomes.

\section{Preoperative characteristics}

Supplementary Fig. 1 shows the forest plots that compare short and standard POEM regarding preoperative characteristics, including Eckardt score, basal LES pressure, 4 sIRP, and barium column diameter. There was no statistically significant difference between short and standard myotomies regarding any of these characteristics.

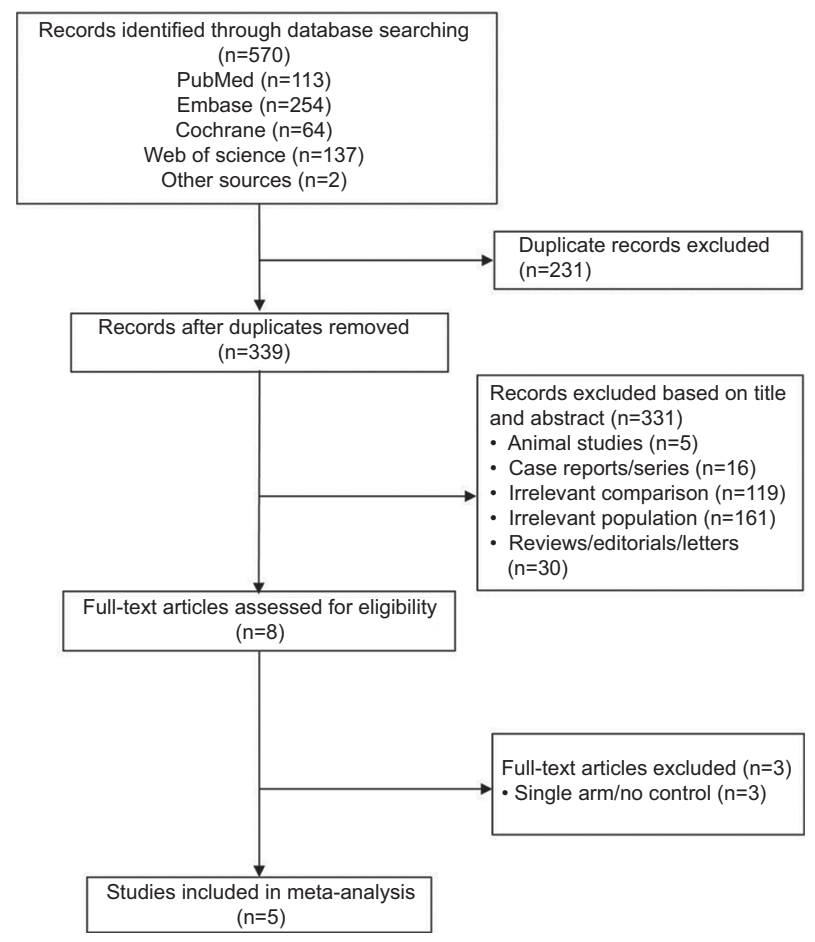

Figure 1 Flow diagram for the selection of studies

\section{Perioperative outcomes}

Table 2 shows the detailed values for myotomy lengths in individual studies. Each study planned for identical gastric myotomy lengths in both groups and a shorter esophageal myotomy in the short myotomy group. When POEM was performed, gastric myotomy lengths were slightly shorter in the short myotomy group but within $1 \mathrm{~cm}$ of the standard myotomy group. Esophageal myotomy lengths were noticeably shorter in the short myotomy group compared with the standard myotomy group. In the short myotomy group, the range of total myotomy was 3-7 cm $(2-6 \mathrm{~cm}$ esophageal and $1-3 \mathrm{~cm}$ gastric). In the standard myotomy group, the range of the total myotomy was $8-25 \mathrm{~cm}(6-20 \mathrm{~cm}$ esophageal and 2-5 cm gastric).

Supplementary Table 3 shows the technical details of POEM in individual studies in terms of orientation and depth of myotomy and the perioperative use of proton pump inhibitors. In terms of orientation of myotomy, some studies used an anterior approach and others a posterior approach. In terms of depth of myotomy, some studies involved a uniform circular myotomy along the length of the tunnel. Other studies involved a progressive myotomy depth, with a circular myotomy in the upper part of the tunnel and a full-thickness myotomy in the lower part.

Fig. 2 shows the forest plots that compare short and standard POEM regarding operation time, length of hospital stay, and perioperative complications. Operation time was significantly shorter in patients who underwent short myotomy compared with standard myotomy (MD - $15.01 \mathrm{~min}$, 95\%CI -20.34 to $-9.67 ; \mathrm{P}<0.001 ; I^{2}=63 \%$ ) (Fig. 2 A). Length of hospital stay was not significantly different between patients who underwent short or standard myotomy (MD 0.25 days, $95 \% \mathrm{CI}-0.14$ to $0.63 ; \mathrm{P}=0.21 ; I^{2}=37 \%$ ) (Fig. $2 \mathrm{~B}$ ). Occurrence of perioperative complications was also similar between the 2 groups (RR 0.68, 95\%CI 0.26-1.75; $\mathrm{P}=0.42 ; I^{2}=63 \%$ ) (Fig. 2C). Supplementary Fig. 2 shows the forest plot comparing short myotomy and standard myotomy regarding perioperative gas-related complications. There was no significant difference between the 2 groups (RR 0.52, 95\%CI 0.07-3.61; $\left.\mathrm{P}=0.51 ; I^{2}=82 \%\right)$. Supplementary Table 4 shows the specific perioperative complications that occurred in individual studies.

\section{Postoperative outcomes}

Fig. 3 shows the forest plots that compare short and standard POEM regarding postoperative outcomes, including clinical success rate, postoperative Eckardt score, change in Eckardt score, postoperative basal LES pressure, postoperative 4sIRP, and postoperative barium column diameter. Clinical success rate was similar between patients who underwent short or standard myotomy (RR 1.02, 95\%CI 0.97-1.09; $\left.\mathrm{P}=0.40 ; I^{2}=0 \%\right)$ (Fig. 3A). Similarly, all other postoperative outcomes did not differ significantly between the 2 groups (Fig. 3B-F). 


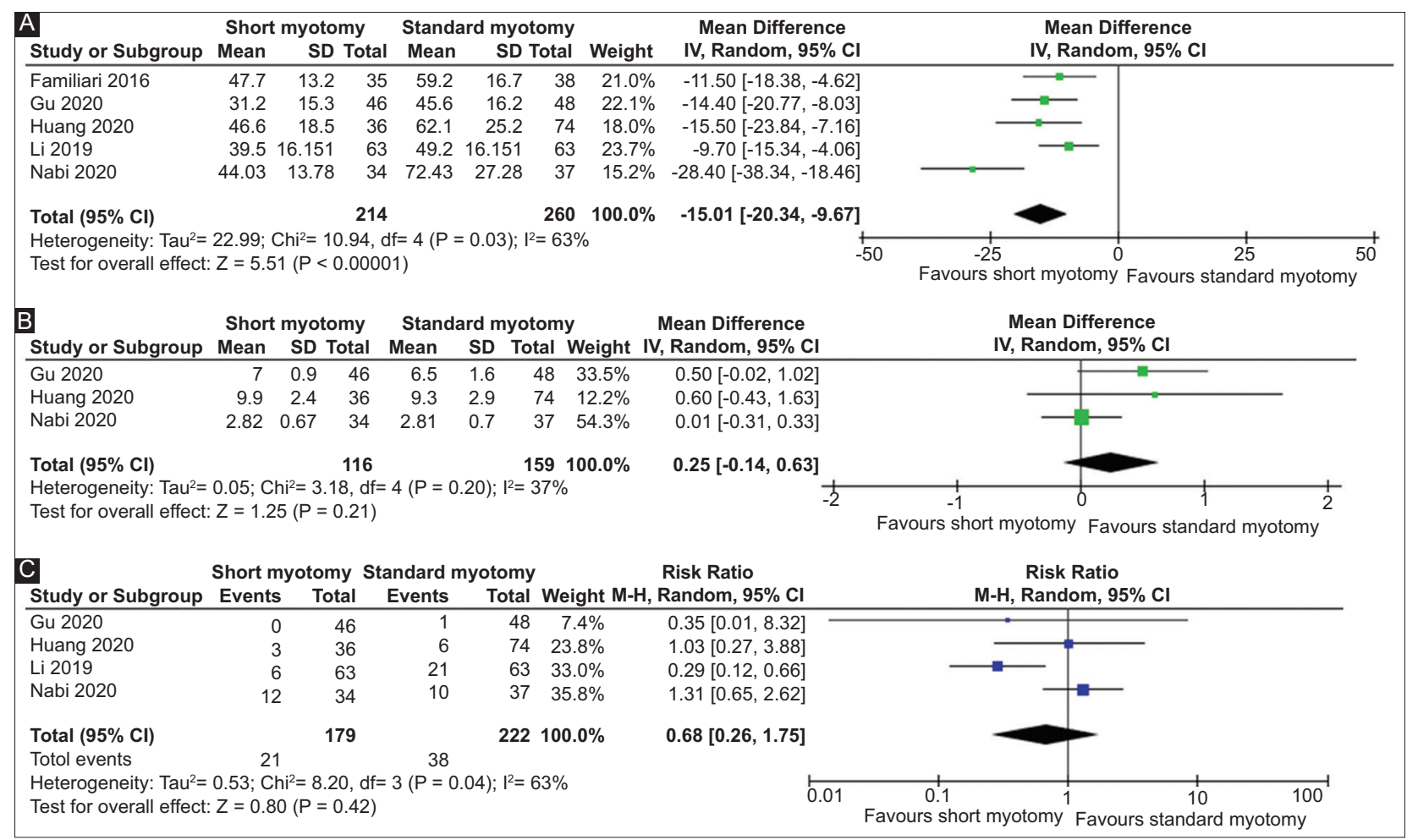

Figure 2 Forest plot comparing short myotomy and standard myotomy regarding perioperative outcomes. (A) Operation time. (B) Length of hospital stay. (C) Perioperative complications

CI, confidence interval

\section{Postoperative GERD}

Fig. 4 shows the forest plots that compare short and standard POEM regarding the occurrence of postoperative GERD, including reflux symptoms, reflux esophagitis on endoscopy, and pathologic acid exposure on $\mathrm{pH}$ monitoring. Reflux symptoms were similar between patients who underwent short or standard myotomy (RR $0.94,95 \% \mathrm{CI} 0.51-1.74 ; \mathrm{P}=0.84$; $I^{2}=48 \%$ ) (Fig. 4A). Reflux esophagitis on endoscopy was significantly less likely to occur in short myotomy compared with standard myotomy (RR 0.61, 95\%CI 0.39-0.98; P=0.04; $I^{2}=0 \%$ ) (Fig. 4B). Pathologic acid exposure on $\mathrm{pH}$ monitoring was also less likely to occur in short myotomy compared with standard myotomy (RR 0.58, 95\%CI 0.36-0.94; $\mathrm{P}=0.03 ; I^{2}=0 \%$ ) (Fig. 4C). Supplementary Table 5 shows the grades of reflux esophagitis in individual studies based on the Los Angeles classification of esophagitis.

\section{Subgroup analysis}

Supplementary Fig. 3 shows the forest plots that compare short and standard POEM regarding clinical success, based on publication status and study design. Short and standard myotomies had similar clinical success rates regardless of whether the studies were in the form of abstracts or publications (Supplementary Fig. 3A), or whether the studies were RCTs or retrospective cohorts (Supplementary Fig. 3B). Supplementary
Fig. 4 shows the forest plots that compare short and standard POEM regarding reflux esophagitis, based on depth of myotomy. Short and standard myotomies had similar rates of reflux esophagitis, regardless of whether circular myotomy was applied along the length of the tunnel, or circular myotomy in the upper part of the tunnel and full thickness in the lower part.

\section{Quality and publication bias assessment}

We assessed the quality of the included studies using the Cochrane RoB 2 tool for RCTs, and the Newcastle-Ottawa scale for cohort studies (Supplementary Fig. 5). Overall, the quality of the cohort studies was excellent. Quality assessment was limited for 1 RCT because it was published as an abstract. There was visible asymmetry in the funnel plot of the studies that reported the clinical success rate, suggesting publication bias (Supplementary Fig. 6).

\section{Discussion}

We performed a systematic review and meta-analysis of studies that compared short and standard POEM in relation to various perioperative and postoperative outcomes. This meta-analysis demonstrated that short and standard POEM had similar short-term clinical success, defined as a postoperative Eckardt score of 3 or lower. Postoperative 


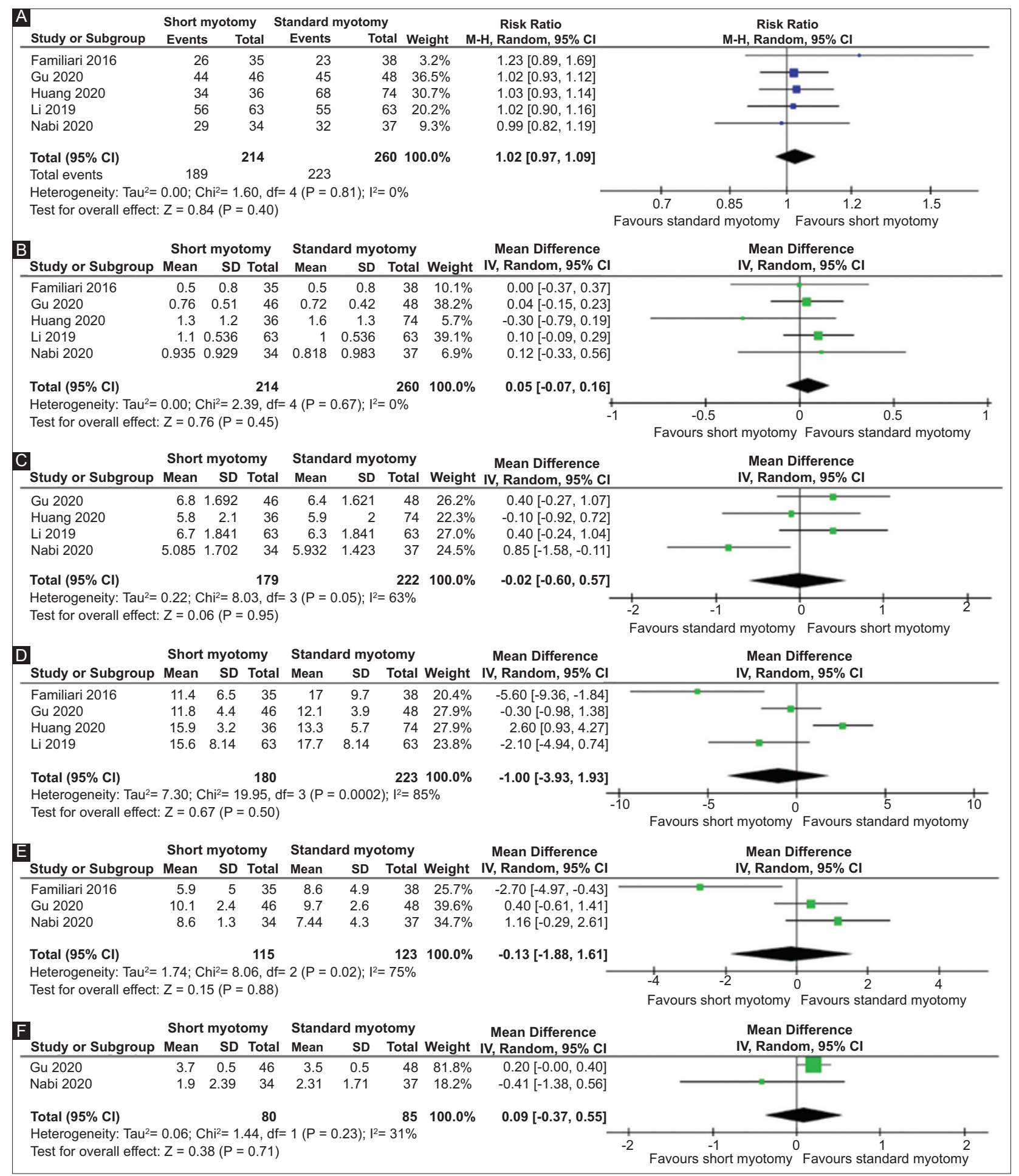

Figure 3 Forest plot comparing short myotomy and standard myotomy regarding postoperative outcomes. (A) Clinical success rate. (B) Postoperative Eckardt score. (C) Change in Eckardt score. (D) Postoperative basal lower esophageal sphincter pressure. (E) Postoperative 4-sec integrated relaxation pressure. (F) Postoperative barium column diameter

CI, confidence interval

manometric and esophagram findings were also comparable, including LES pressure, 4sIRP, and barium column diameter. A shorter myotomy shortened operation time significantly compared with standard myotomy, but this did not affect the occurrence of perioperative complications or the length of hospital stay.

Postoperative GERD is the most common adverse event that complicates POEM in the long term. A modified POEM 


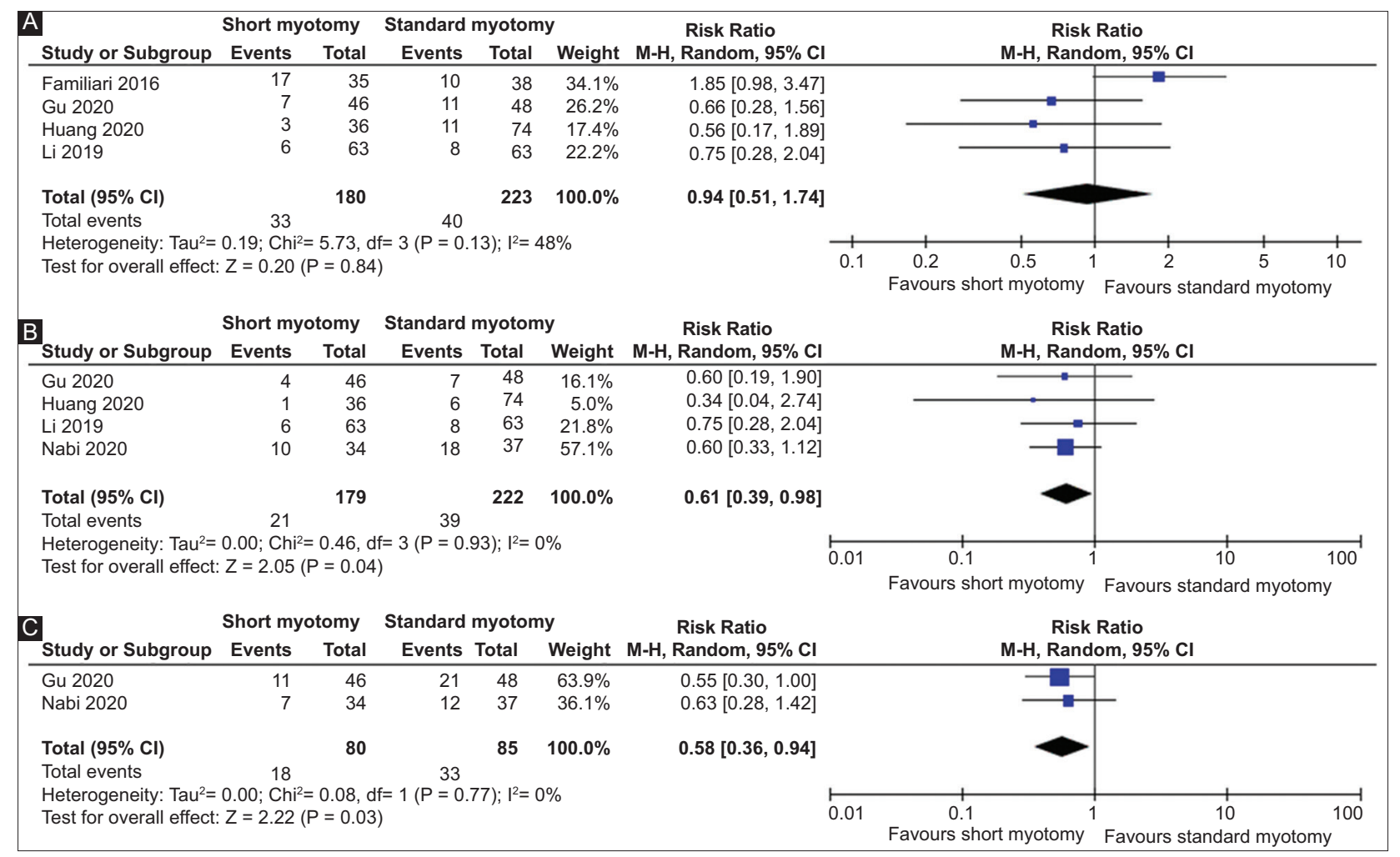

Figure 4 Forest plot comparing short myotomy and standard myotomy regarding postoperative gastroesophageal reflux disease. (A) Reflux symptoms. (B) Reflux esophagitis on endoscopy. (C) Pathologic acid exposure on $\mathrm{pH}$ monitoring CI, confidence interval

with short myotomy may theoretically reduce the risk of postoperative GERD. In this meta-analysis, subjective reporting of reflux symptoms was similar between short and standard myotomies. However, objective assessment endoscopically and through 24-h pH monitoring showed that short myotomy had a lower risk of reflux esophagitis and pathologic acid exposure, respectively. This demonstrates that POEM with a shorter myotomy is associated with a lower risk of postoperative GERD compared with standard myotomy in the short-term setting. The exact mechanism by which a shorter myotomy reduces the occurrence of GERD is not clear. One possible explanation is preservation of a longer segment of the circular and longitudinal muscle fibers, improving the anti-reflux function of the LES.

Inoue et al presented the first human experience that studied the efficacy of POEM in achalasia [3]. To identify the optimal myotomy length, 2 subsets of patients underwent POEM with different myotomy lengths. The first 7 patients underwent a relatively shorter myotomy with an average length of 4.9 (range 3-7) $\mathrm{cm}$. In the latter 10 patients, myotomy length was extended to an average of 10.4 (range $7-15) \mathrm{cm}$. When these 2 subgroups were compared, the postoperative dysphagia score was lower in the latter patients, implying that a longer myotomy was more effective in improving symptoms. Therefore, the authors recommended a long myotomy approach with a minimum length of $7 \mathrm{~cm}$. Since then, most studies that investigated the effectiveness of POEM employed the long myotomy approach [17-19].

The first report of a modified POEM with a shorter myotomy was a prospective study by Wang et al [6]. They hypothesized that a shorter myotomy could achieve similar clinical outcomes, but with a lower incidence of complications and a shorter operation time. They used a short myotomy with an average length of 5.4 (range $3.5-7.5$ ) cm. In their assessment, this was long enough to fully cut the LES, which has an average length of 3.2 (range $2.4-4.0$ ) $\mathrm{cm}$. Their approach was highly successful in the short term, with a clinical success rate of $100 \%$. Seven of the 46 patients (15.2\%) developed GERD during follow up, but this was lower than the incidence of GERD in studies that utilized a long myotomy [17-19].

Recently, a few studies have directly compared POEM with short myotomy and long myotomy [12-16]. These studies hypothesized that a shorter myotomy could be as effective as long myotomy, but with a lower risk of postoperative GERD. The individual studies found similar clinical success rates between the 2 myotomy lengths but did not detect a difference in terms of postoperative GERD. By pooling data across studies, our meta-analysis showed that a shorter myotomy was, in fact, associated with a lower incidence of postoperative GERD.

Based on high-resolution manometry findings, 3 achalasia subtypes have been described: type I or classic achalasia with minimal contractility in the esophageal body; type II with periods of pan-esophageal pressurization; and type III with spastic contractions [20]. Multiple studies have shown that the choice of therapy and treatment outcomes depend on subtypes of achalasia. For example, POEM, LHM, and pneumatic dilation are very effective for type I and type II achalasia [21]. However, LHM and 
Table 1 Characteristics of studies included in the meta-analysis

\begin{tabular}{|c|c|c|c|c|c|c|c|c|c|c|}
\hline $\begin{array}{l}\text { Author, } \\
\text { year } \\
\text { [Ref.] }\end{array}$ & Country & $\begin{array}{c}\text { Study } \\
\text { period }\end{array}$ & $\begin{array}{l}\text { Study } \\
\text { design }\end{array}$ & $\begin{array}{l}\text { Publication } \\
\text { status }\end{array}$ & $\begin{array}{l}\text { Achalasia } \\
\text { subtypesa }\end{array}$ & $\begin{array}{c}\text { Sample } \\
\text { size }\end{array}$ & $\begin{array}{c}\text { Short/ } \\
\text { standard } \\
\text { myotomy }\end{array}$ & $\begin{array}{c}\text { Male/ } \\
\text { female }\end{array}$ & $\begin{array}{l}\text { Age, mean, } \\
\text { years }\end{array}$ & $\begin{array}{l}\text { Follow } \\
\text { up, mean, } \\
\text { months }\end{array}$ \\
\hline $\begin{array}{l}\text { Familiari, } \\
2016 \text { [12] }\end{array}$ & Italy & $\begin{array}{c}\text { Ended } \\
2015\end{array}$ & RCT & Abstract & Type I and II & 73 & $35 / 38$ & NR & NR & 8 \\
\hline $\begin{array}{l}\mathrm{Gu}, 2020 \\
{[13]}\end{array}$ & China & $\begin{array}{c}2018- \\
2019\end{array}$ & RCT & Publication & Type II & 94 & $46 / 48$ & $44 / 50$ & $\begin{array}{l}\text { Short: } 43.6 \\
\text { Standard: } \\
42.8\end{array}$ & 12 \\
\hline $\begin{array}{l}\text { Huang, } \\
2020 \text { [14] }\end{array}$ & China & $\begin{array}{l}2011- \\
2017\end{array}$ & $\mathrm{RC}$ & Publication & $\begin{array}{c}\text { Type I: } 34.5 \% \\
\text { Type II: } \\
65.5 \%\end{array}$ & 110 & $36 / 74$ & $59 / 51$ & $\begin{array}{l}\text { Short: } 40.8 \\
\text { Standard: } \\
\quad 37.7\end{array}$ & $\begin{array}{c}\text { Short: } 26.8 \\
\text { Standard: } \\
29.5\end{array}$ \\
\hline $\begin{array}{l}\mathrm{Li}, 2019 \\
{[15]}\end{array}$ & China & $\begin{array}{c}2013- \\
2016\end{array}$ & $\mathrm{RC}$ & Publication & $\begin{array}{l}\text { Type I: } 19.8 \% \\
\text { Type II: } \\
77.0 \% \\
\text { Type III: } 3.2 \%\end{array}$ & 126 & $63 / 63$ & $54 / 72$ & $\begin{array}{l}\text { Short: } 49.3 \\
\text { Standard: } \\
45.9\end{array}$ & $\begin{array}{c}\text { Short: } 20.1 \\
\text { Standard: } \\
23.6\end{array}$ \\
\hline $\begin{array}{l}\text { Nabi, } \\
2020 \text { [16] }\end{array}$ & India & $\begin{array}{l}2017- \\
2019\end{array}$ & RCT & Publication & $\begin{array}{c}\text { Type I: } 35.2 \% \\
\text { Type II: } \\
64.8 \%\end{array}$ & 71 & $34 / 37$ & $42 / 29$ & $\begin{array}{l}\text { Short: } 40.1 \\
\text { Standard: } \\
41.3\end{array}$ & 12 \\
\hline
\end{tabular}

${ }^{2}$ Subtypes according to the Chicago classification of achalasia

$N R$, not reported; $R C$, retrospective cohort; $R C T$, randomized controlled trial

Table 2 Detailed values for myotomy lengths in individual studies

\begin{tabular}{|c|c|c|c|c|c|c|}
\hline \multirow[t]{2}{*}{ Author, year [Ref.] } & \multicolumn{3}{|c|}{$\begin{array}{l}\text { Short myotomy length } \\
\text { Mean } \pm \text { SD (range), cm }\end{array}$} & \multicolumn{3}{|c|}{$\begin{array}{l}\text { Standard myotomy length } \\
\text { Mean } \pm \mathrm{SD} \text { (range), } \mathrm{cm}\end{array}$} \\
\hline & Esophageal & Gastric & Total & Esophageal & Gastric & Total \\
\hline \multicolumn{7}{|c|}{ Planned myotomy lengths } \\
\hline Familiari, 2016 [12] & 5 & 3 & 8 & 10 & 3 & 13 \\
\hline $\mathrm{Gu}, 2020[13]$ & $3-4$ & $2-3$ & $5-7$ & $7-8$ & $2-3$ & $9-11$ \\
\hline Huang, $2020[14]$ & $<4$ & $2-3$ & $<7$ & $>4$ & $2-3$ & $>7$ \\
\hline $\mathrm{Li}, 2019[15]$ & $4-6$ & 2 & $6-8$ & $8-12$ & 2 & $10-14$ \\
\hline Nabi, $2020[16]$ & $<3$ & $2-4$ & $<5-7$ & $>6$ & $2-4$ & $>8-10$ \\
\hline \multicolumn{7}{|c|}{ Reported myotomy lengths ${ }^{\mathrm{a}}$} \\
\hline Familiari, 2016 [12] & NR & NR & NR & NR & NR & NR \\
\hline $\mathrm{Gu}, 2020[13]$ & NR & NR & $5.66 \pm 0.14$ & NR & NR & $10.14 \pm 0.54$ \\
\hline Huang, $2020[14]$ & $4 \pm 0.7(3-6)$ & $2.1 \pm 0.3(1-3)$ & $6.0 \pm 0.6(5-7)$ & $8.2 \pm 2.7(6-20)$ & $3.2 \pm 1.2(2-5)$ & $11.5 \pm 3.1(8-25)$ \\
\hline $\mathrm{Li}, 2019$ [15] & $2.9(2-4)$ & $2.0(1-3)$ & $4.8(3-6)$ & $6.9(5-9)$ & $2.3(2-4)$ & $9.2(8-11)$ \\
\hline Nabi, $2020[16]$ & $2.76 \pm 0.41$ & $2.70 \pm 0.73$ & NR & $7.97 \pm 2.40$ & $2.84 \pm 0.63$ & NR \\
\hline
\end{tabular}

aP-value was $<0.001$ for all comparisons between short and standard myotomies, except for the gastric myotomy length comparison for Nabi where the P-value was 0.389

$N R$, not reported; SD, standard deviation

pneumatic dilation are associated with a lower success rate for type III achalasia [22], and multiple gastrointestinal societies are now recommending POEM as the preferred therapy in these cases $[21,23,24]$. Presumably, POEM can improve the success rate in type III achalasia by applying an esophageal myotomy where the length of myotomy is tailored to the spastic segment [22]. Therefore, patients with type III achalasia might benefit from a longer myotomy. In our meta-analysis, Li et al included 4 patients with type III achalasia, and these make up $0.84 \%$ of the total number of patients included in this meta-analysis [15]. Given the recent literature and the small number of patients with type III achalasia included in this meta-analysis, our conclusions probably do not apply to type III achalasia and a short myotomy is not recommended.

Some studies have examined the effectiveness of a longer gastric myotomy during LHM [25,26]. A prospective study compared extended gastric myotomy, defined as a $3-\mathrm{cm}$ incision into the stomach, with standard gastric myotomy, defined as a 1-2-cm incision into the stomach. A total of 52 patients were followed for a median of 45 months in the extended myotomy group and 46 months in the standard 
myotomy group. The extended myotomy group had lower postoperative dysphagia severity scores than the standard myotomy group [26]. This questions whether a shorter myotomy may decrease the success rate of POEM if it involves a shorter gastric myotomy. In the individual studies included in this meta-analysis, the authors planned for gastric myotomy lengths that were similar between the short and standard myotomy groups. Eventually, the gastric myotomy lengths were comparable and the differences between the myotomy lengths of short and standard POEM were mainly attributed to esophageal myotomy.

There are several limitations to our meta-analysis. First, the follow-up duration ranged between 8 months and 2 years, which may have not been long enough to adequately compare the efficacy of the 2 myotomy lengths. A longer follow-up duration is required to ensure the 2 myotomy lengths are comparable in the long-term setting. Second, our conclusions mainly apply to type I and type II achalasia, and a short myotomy might not be useful in type III achalasia. Third, only 5 studies were retrieved by our search strategy, which compelled us to include both cohort studies and RCTs in the same analysis. We adjusted for this by performing a subgroup analysis for the primary outcome based on study design, which showed no difference between retrospective cohort studies and RCTs. Fourth, 3 of the 5 included studies that originated from China, which could limit the generalizability of our conclusions. Fifth, blinding of endoscopists was not possible in individual studies because of the nature of the intervention, which increased the risk of performance bias in all studies. Sixth, 1 of the included RCTs was an abstract, for which quality assessment was lacking because of limited information about the methodology used. Seventh, although we included 474 patients in our meta-analysis, some outcomes were not reported by all studies. For example, 3 outcomes were only reported by 2 studies including 165 participants, which may affect the accuracy of our conclusions. Finally, given the heterogeneity of the included studies, the definition of short myotomy remains imprecise and cannot be accurately outlined by this meta-analysis. Nevertheless, myotomy lengths in the short myotomy group ranged between $3 \mathrm{~cm}$ and $7 \mathrm{~cm}$ across studies. Therefore, we think that the optimal length of short myotomy may lie somewhere between $3 \mathrm{~cm}$ and $7 \mathrm{~cm}$, which corresponds to the range of myotomy lengths utilized by Inoue et al in their initial study [3].

In conclusion, POEM using short myotomy is comparable with standard myotomy in terms of efficacy and safety in the short-term setting. A shorter myotomy requires a shorter procedure time and reduces the incidence of postoperative GERD. Our results are not conclusive and are limited by a short follow-up duration, the small number of patients and the lack of a universal definition of short myotomy. Future RCTs should determine whether efficacy remains equivalent after many years of follow up and whether the recurrence rate is higher in the short myotomy group. Finally, future studies should compare multiple myotomy lengths to determine the optimal length that achieves the greatest balance between efficacy and safety.

\section{Summary Box}

\section{What is already known:}

- Peroral endoscopic myotomy (POEM) is a very effective treatment for esophageal achalasia

- POEM carries a high risk of postoperative gastroesophageal reflux disease (GERD)

- A modified POEM with a shorter myotomy might decrease the occurrence of postoperative GERD when compared with standard (long) myotomy

- Recent studies could not demonstrate a statistically significant difference between the 2 myotomy lengths

\section{What the new findings are:}

- POEM with short myotomy reduces the occurrence of postoperative GERD

- Short POEM reduced operation time compared with standard POEM

- Short POEM is as effective as standard POEM in terms of short-term clinical success rate, complications, and postoperative manometric and esophagogram findings

\section{References}

1. Reynolds JC, Parkman HP. Achalasia. Gastroenterol Clin North Am 1989;18:223-255.

2. Spiess AE, Kahrilas PJ. Treating achalasia: from whalebone to laparoscope. JAMA 1998;280:638-642.

3. Inoue $\mathrm{H}, \mathrm{Minami} \mathrm{H}$, Kobayashi $\mathrm{Y}$, et al. Peroral endoscopic myotomy (POEM) for esophageal achalasia. Endoscopy 2010;42:265-271.

4. Schlottmann F, Luckett DJ, Fine J, Shaheen NJ, Patti MG. Laparoscopic Heller myotomy versus peroral endoscopic myotomy (POEM) for achalasia: a systematic review and meta-analysis. Ann Surg 2018;267:451-460.

5. Richards WO, Torquati A, Holzman MD, et al. Heller myotomy versus Heller myotomy with Dor fundoplication for achalasia: a prospective randomized double-blind clinical trial. Ann Surg 2004;240:405-412.

6. Wang J, Tan N, Xiao Y, et al. Safety and efficacy of the modified peroral endoscopic myotomy with shorter myotomy for achalasia patients: a prospective study. Dis Esophagus 2015;28:720-727.

7. Moher D, Liberati A, Tetzlaff J, Altman DG; PRISMA Group. Preferred reporting items for systematic reviews and metaanalyses: the PRISMA statement. PLoS Med 2009;6:e1000097.

8. Stroup DF, Berlin JA, Morton SC, et al. Meta-analysis of observational studies in epidemiology: a proposal for reporting. Meta-analysis Of Observational Studies in Epidemiology (MOOSE) group. JAMA 2000;283:2008-2012.

9. Higgins JP, Thompson SG, Deeks JJ, Altman DG. Measuring inconsistency in meta-analyses. BMJ 2003;327:557-560.

10. Sterne JAC, Savović J, Page MJ, et al. RoB 2: a revised tool for assessing risk of bias in randomised trials. BMJ 2019;366:14898.

11. Deeks JJ, Dinnes J, D’Amico R, et al; European Carotid Surgery Trial Collaborative Group. Evaluating non-randomised intervention 
studies. Health Technol Assess 2003;7:iii-x.

12. Familiari P, Cali A, Landi R, et al. Long vs short POEM for the treatment of achalasia. Interim analysis of a randomized controlled trial. Dig Liver Dis 2016;48:e90.

13. Gu L, Ouyang Z, Lv L, Liang C, Zhu H, Liu D. Safety and efficacy of peroral endoscopic myotomy with standard myotomy versus short myotomy for treatment-naive patients with type II achalasia: a prospective randomized trial. Gastrointest Endosc 2021;93:13041312.

14. Huang S, Ren Y, Peng W, et al. Peroral endoscopic shorter versus longer myotomy for the treatment of achalasia: a comparative retrospective study. Esophagus 2020;17:477-483.

15. Li L, Chai N, Linghu E, et al. Safety and efficacy of using a short tunnel versus a standard tunnel for peroral endoscopic myotomy for Ling type IIc and III achalasia: a retrospective study. Surg Endosc 2019;33:1394-1402.

16. Nabi Z, Ramchandani M, Sayyed M, et al. Comparison of short versus long esophageal myotomy in cases with idiopathic achalasia: a randomized controlled trial. J Neurogastroenterol Motil 2021;27:63-70.

17. Zhou PH, Cai MY, Yao LQ, et al. [Peroral endoscopic myotomy for esophageal achalasia: report of 42 cases]. Zhonghua Wei Chang Wai Ke Za Zhi 2011;14:705-708.

18. von Renteln $\mathrm{D}$, Inoue $\mathrm{H}$, Minami $\mathrm{H}$, et al. Peroral endoscopic myotomy for the treatment of achalasia: a prospective single center study. Am J Gastroenterol 2012;107:411-417.

19. Swanström LL, Rieder E, Dunst CM. A stepwise approach and early clinical experience in peroral endoscopic myotomy for the treatment of achalasia and esophageal motility disorders. J Am Coll Surg 2011;213:751-756.

20. Patel DA, Lappas BM, Vaezi MF. An overview of achalasia and its subtypes. Gastroenterol Hepatol (N Y) 2017;13:411-421.

21. Khashab MA, Vela MF, Thosani N, et al. ASGE guideline on the management of achalasia. Gastrointest Endosc 2020;91:213-227.

22. Kumbhari V, Tieu AH, Onimaru M, et al. Peroral endoscopic myotomy (POEM) vs laparoscopic Heller myotomy (LHM) for the treatment of Type III achalasia in 75 patients: a multicenter comparative study. Endosc Int Open 2015;3:E195-E201.

23. Kahrilas PJ, Katzka D, Richter JE. Clinical practice update: the use of per-oral endoscopic myotomy in achalasia: expert review and best practice advice from the AGA institute. Gastroenterology 2017;153:1205-1211.

24. Kahrilas PJ, Bredenoord AJ, Fox M, et al; International Working Group for Disorders of Gastrointestinal Motility and Function. Expert consensus document: Advances in the management of oesophageal motility disorders in the era of high-resolution manometry: a focus on achalasia syndromes. Nat Rev Gastroenterol Hepatol 2017;14:677-688.

25. Oelschlager BK, Chang L, Pellegrini CA. Improved outcome after extended gastric myotomy for achalasia. Arch Surg 2003;138:490-495.

26. Wright AS, Williams CW, Pellegrini CA, Oelschlager BK. Longterm outcomes confirm the superior efficacy of extended Heller myotomy with Toupet fundoplication for achalasia. Surg Endosc 2007:21:713-718. 


\section{Supplementary material}

Supplementary Table 1 Detailed search strategy

\begin{tabular}{|c|c|c|c|}
\hline Database & Search & Query & Items \\
\hline \multirow[t]{5}{*}{ PubMed } & $\# 1$ & 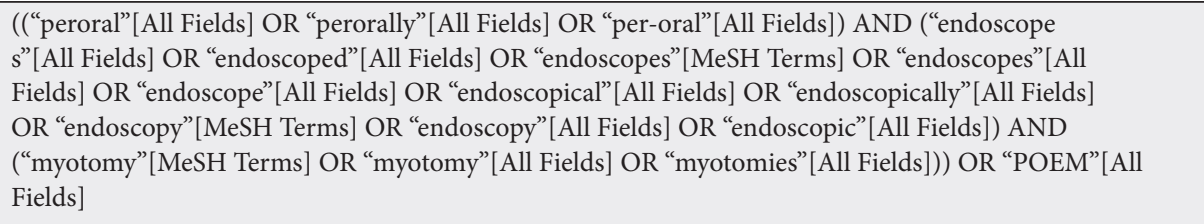 & 1954 \\
\hline & $\# 2$ & $\begin{array}{l}\text { "esophageal achalasia"[MeSH Terms] OR ("esophageal”[All Fields] AND "achalasia”[All Fields]) OR } \\
\text { "esophageal achalasia"[All Fields] OR "achalasia"[All Fields] }\end{array}$ & 8677 \\
\hline & $\# 3$ & "short"[All Fields] OR "shorts"[All Fields] OR "shorter"[All Fields] & 983,747 \\
\hline & $\# 4$ & \#1 AND \#2 AND \#3 & 170 \\
\hline & $\# 5$ & $\begin{array}{l}\text { \#4 NOT ("case reports"[Publication Type] OR "editorial”[Publication Type] OR "guideline" [Publication } \\
\text { Type] OR "introductory journal article"[Publication Type] OR "meta analysis"[Publication Type] OR } \\
\text { "news"[Publication Type] OR "practice guideline"[Publication Type] OR "review"[Publication Type] OR } \\
\text { "systematic review"[Publication Type]) }\end{array}$ & 113 \\
\hline \multirow[t]{6}{*}{ Embase } & $\# 1$ & (peroral OR 'per oral') AND endoscopic AND ('myotomy'/exp OR myotomy) OR poem & 3792 \\
\hline & $\# 2$ & achalasia & 13522 \\
\hline & $\# 3$ & short OR shorter & 1927915 \\
\hline & $\# 4$ & \#1 AND \#2 AND \#3 & 476 \\
\hline & $\# 5$ & $\begin{array}{l}\text { \#4 NOT ('animal cell'/de OR 'animal experiment'/de OR 'animal model'/de OR 'animal tissue'/de OR } \\
\text { 'case report'/de OR 'clinical protocol'/de OR 'diagnostic test accuracy study'/de OR 'meta analysis'/de OR } \\
\text { 'methodology'/de OR 'nonhuman'/de OR 'practice guideline'/de OR 'questionnaire'/de OR 'systematic } \\
\text { review'/de OR 'chapter'/it OR 'editorial'/it OR 'erratum'/it OR 'note'/it OR 'review'/it OR 'short survey'/it) }\end{array}$ & 340 \\
\hline & \#6 & \#5 AND [embase]/lim NOT ([embase]/lim AND [medline]/lim) & 254 \\
\hline $\begin{array}{l}\text { Web of } \\
\text { science }\end{array}$ & $\# 1$ & $\begin{array}{l}\text { (((((peroral OR per-oral) AND endoscopic AND myotomy) OR POEM) AND (achalasia)) AND (short OR } \\
\text { shorter)) } \\
\text { Refined by: [excluding] DOCUMENT TYPES: (REVIEW OR EDITORIAL MATERIAL OR LETTER) }\end{array}$ & 137 \\
\hline Cochrane & $\# 1$ & (poem OR myotomy) AND achalasia AND (short OR shorter) & 64 \\
\hline
\end{tabular}


Supplementary Table 2 Summary of pooled effect estimates of preoperative, perioperative, and postoperative outcomes

\begin{tabular}{|c|c|c|c|c|c|c|}
\hline Outcome & Studies & Participants & Statistical method & Estimate $[95 \% \mathrm{CI}]$ & P-value & $I^{2}$ \\
\hline Preoperative Eckardt score & 4 & 401 & MD (IV, Random, 95\%CI) & $-0.03[-0.67,0.61]$ & 0.92 & $73 \%$ \\
\hline Preoperative basal LES pressure & 3 & 330 & MD (IV, Random, 95\%CI) & $0.75[-1.05,2.55]$ & 0.41 & $0 \%$ \\
\hline Preoperative 4 sIRP & 2 & 165 & MD (IV, Random, 95\%CI) & $0.86[-2.23,3.95]$ & 0.59 & $31 \%$ \\
\hline Preoperative barium column diameter & 3 & 275 & MD (IV, Random, 95\%CI) & $0.33[-0.03,0.69]$ & 0.08 & $0 \%$ \\
\hline Operation time & 5 & 474 & MD (IV, Random, 95\%CI) & $-15.01[-20.34,-9.67]$ & $<0.001$ & $63 \%$ \\
\hline Length of hospital stay & 3 & 275 & MD (IV, Random, 95\%CI) & $0.25[-0.14,0.63]$ & 0.21 & $37 \%$ \\
\hline Perioperative complications & 4 & 401 & RR (MH, Random, 95\%CI) & $0.68[0.26,1.75]$ & 0.42 & $63 \%$ \\
\hline Clinical success & 5 & 474 & RR (MH, Random, 95\%CI) & $1.02[0.97,1.09]$ & 0.40 & $0 \%$ \\
\hline Postoperative Eckardt score & 5 & 474 & MD (IV, Random, 95\%CI) & $0.05[-0.07,0.16]$ & 0.45 & $0 \%$ \\
\hline Change in Eckardt score & 4 & 401 & MD (IV, Random, 95\%CI) & $-0.02[-0.60,0.57]$ & 0.95 & $63 \%$ \\
\hline Postoperative basal LES pressure & 4 & 403 & MD (IV, Random, 95\%CI) & $-1.00[-3.93,1.93]$ & 0.50 & $85 \%$ \\
\hline Postoperative 4sIRP & 3 & 238 & MD (IV, Random, 95\%CI) & $-0.13[-1.88,1.61]$ & 0.88 & $75 \%$ \\
\hline Postoperative barium column diameter & 2 & 165 & MD (IV, Random, 95\%CI) & $0.09[-0.37,0.55]$ & 0.71 & $31 \%$ \\
\hline Reflux symptoms & 4 & 403 & RR (MH, Random, 95\%CI) & $0.94[0.51,1.74]$ & 0.84 & $48 \%$ \\
\hline Reflux esophagitis on endoscopy & 4 & 401 & RR (MH, Random, 95\%CI) & $0.61[0.39,0.98]$ & 0.04 & $0 \%$ \\
\hline $\begin{array}{l}\text { Pathologic acid exposure on } \mathrm{pH} \\
\text { monitoring }\end{array}$ & 2 & 165 & RR (MH, Random, 95\%CI) & $0.58[0.36,0.94]$ & 0.03 & $0 \%$ \\
\hline
\end{tabular}

Supplementary Table 3 Technical details of POEM in individual studies

\begin{tabular}{|c|c|c|c|c|}
\hline \multirow{2}{*}{$\begin{array}{l}\text { Author, year } \\
\text { [Suppl. Ref.] }\end{array}$} & \multirow{2}{*}{$\begin{array}{l}\text { Orientation } \\
\text { of myotomy }\end{array}$} & \multirow[t]{2}{*}{ Depth of myotomy } & \multicolumn{2}{|l|}{ PPI use } \\
\hline & & & Inpatient & Outpatient \\
\hline $\begin{array}{l}\text { Familiari, } \\
2016[1]\end{array}$ & NR & NR & NR & NR \\
\hline $\mathrm{Gu}, 2020$ [2] & $\begin{array}{l}\text { Posterior } \\
\text { approach }\end{array}$ & Circular myotomy & IV PPI & $\begin{array}{l}\text { Oral PPI } \\
\text { for } 2 \text { weeks }\end{array}$ \\
\hline $\begin{array}{l}\text { Huang, } \\
2020[3]\end{array}$ & NR & Circular myotomy & NR & $\begin{array}{l}\text { Oral PPI } \\
\text { for } 2 \text { weeks }\end{array}$ \\
\hline $\mathrm{Li}, 2019[4]$ & Variable & $\begin{array}{l}\text { Progressively increased from circular myotomy at the upper end of myotomy to } \\
\text { full-thickness myotomy at the lower end }\end{array}$ & IV PPI & $\begin{array}{l}\text { Oral PPI } \\
\text { for } 4 \text { weeks }\end{array}$ \\
\hline Nabi, 2020 [5] & $\begin{array}{l}\text { Anterior } \\
\text { approach }\end{array}$ & $\begin{array}{l}\text { Circular myotomy in the upper part of myotomy and full-thickness myotomy } \\
\text { from } 2-3 \mathrm{~cm} \text { above the gastroesophageal junction until the lower end }\end{array}$ & NR & NR \\
\hline
\end{tabular}

IV, intravenous; NR, not reported; POEM, peroral endoscopic myotomy; PPI, proton pump inhibitor 
Supplementary Table 4 Specific perioperative complications that occurred in individual studies

\begin{tabular}{|c|c|c|c|}
\hline Author, year [Suppl. Ref.] & Complication & Short myotomy & Standard myotomy \\
\hline Familiari, $2016[1]$ & NR & NR & NR \\
\hline $\mathrm{Gu}, 2020[2]$ & Mucosal injury & 0 & 1 \\
\hline Huang, $2020[3]$ & $\begin{array}{l}\text { Mucosal perforation } \\
\text { Major bleeding } \\
\text { Pneumothorax }\end{array}$ & $\begin{array}{l}0 \\
2 \\
1\end{array}$ & $\begin{array}{l}1 \\
3 \\
2\end{array}$ \\
\hline $\mathrm{Li}, 2019[4]$ & $\begin{array}{l}\text { Mucosal injury } \\
\text { Pneumothorax } \\
\text { Pneumoperitoneum } \\
\text { Pneumomediastinum } \\
\text { Subcutaneous emphysema }\end{array}$ & $\begin{array}{l}4 \\
0 \\
2 \\
0 \\
0\end{array}$ & $\begin{array}{c}5 \\
1 \\
3 \\
1 \\
14\end{array}$ \\
\hline Nabi, 2020 [5] & $\begin{array}{l}\text { Mucosal injury requiring clipping } \\
\text { Minor bleeding } \\
\text { Subcutaneous emphysema } \\
\text { Capnoperitoneum requiring decompression } \\
\text { Retroperitoneal } \mathrm{CO}_{2}\end{array}$ & $\begin{array}{c}1 \\
12 \\
4 \\
3 \\
4\end{array}$ & $\begin{array}{c}1 \\
17 \\
4 \\
3 \\
2\end{array}$ \\
\hline
\end{tabular}

NR, not reported

Supplementary Table 5 Grades of reflux esophagitis in individual studies based on the LA classification of esophagitis

\begin{tabular}{lcccc}
\hline $\begin{array}{l}\text { Author, year } \\
\text { [Suppl. Ref.] }\end{array}$ & LA grade & Total & $\begin{array}{c}\text { Short } \\
\text { myotomy }\end{array}$ & $\begin{array}{c}\text { Standard } \\
\text { myotomy }\end{array}$ \\
\hline Familiari, 2016 [1] & NR & NR & NR & NR \\
Gu, 2020 [2] & A and B & 10 & NR & NR \\
& C & 1 & NR & NR \\
Huang, 2020 [3] & A & 5 & 1 & 4 \\
& B & 2 & 0 & 2 \\
Li, 2019 [4] & NR & NR & NR & NR \\
Nabi, 2020 [5] & A & 13 & 5 & 8 \\
& B & 14 & 5 & 9 \\
\hline
\end{tabular}

LA, Los Angeles; NR, not reported 


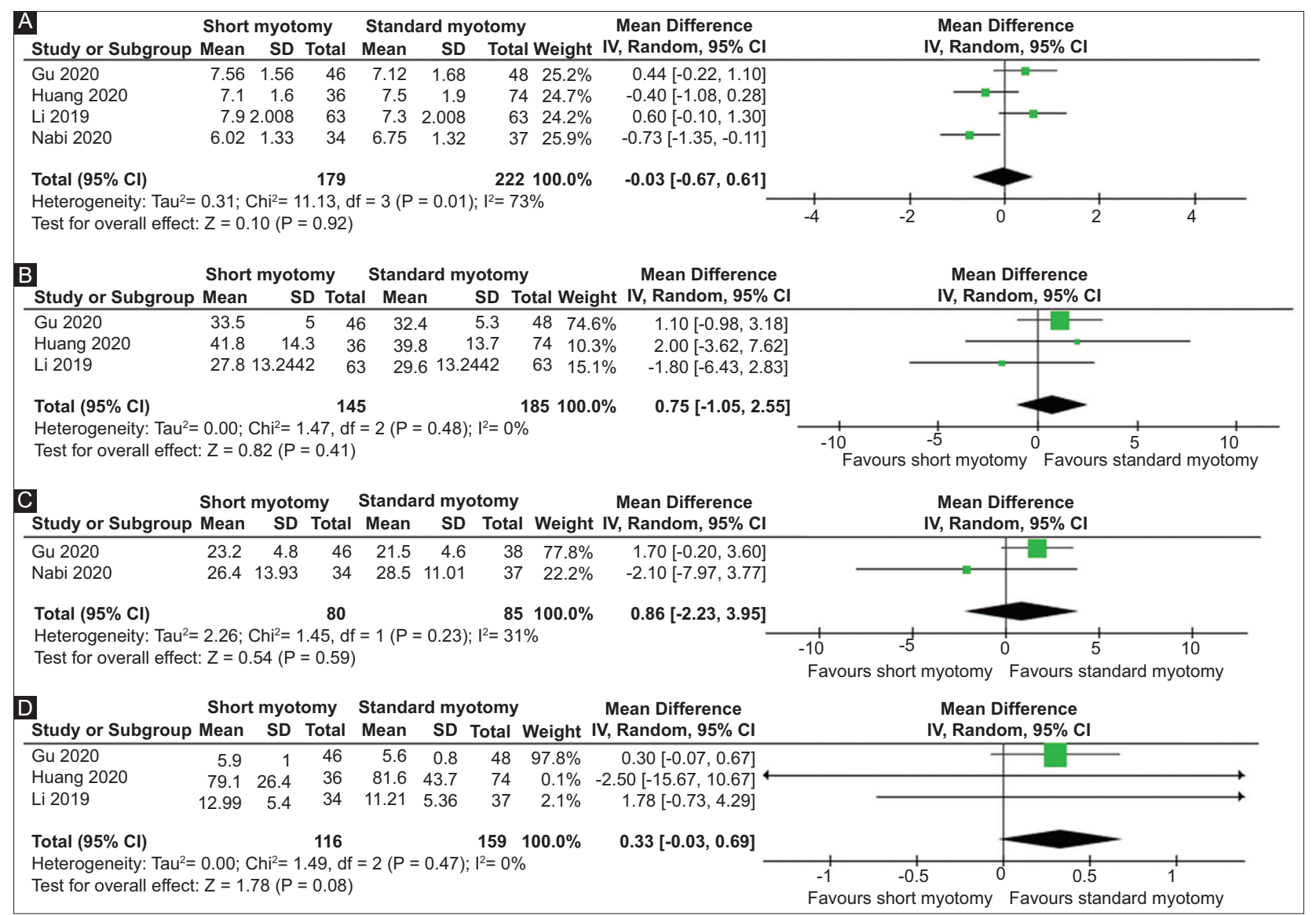

Supplementary Figure 1 Forest plots comparing short myotomy and standard myotomy regarding preoperative characteristics. (A) Preoperative Eckardt score. (B) Preoperative basal lower esophageal sphincter pressure. (C) Pre-operative 4-sec integrated relaxation pressure. (D) Preoperative barium column diameter

CI, confidence interval

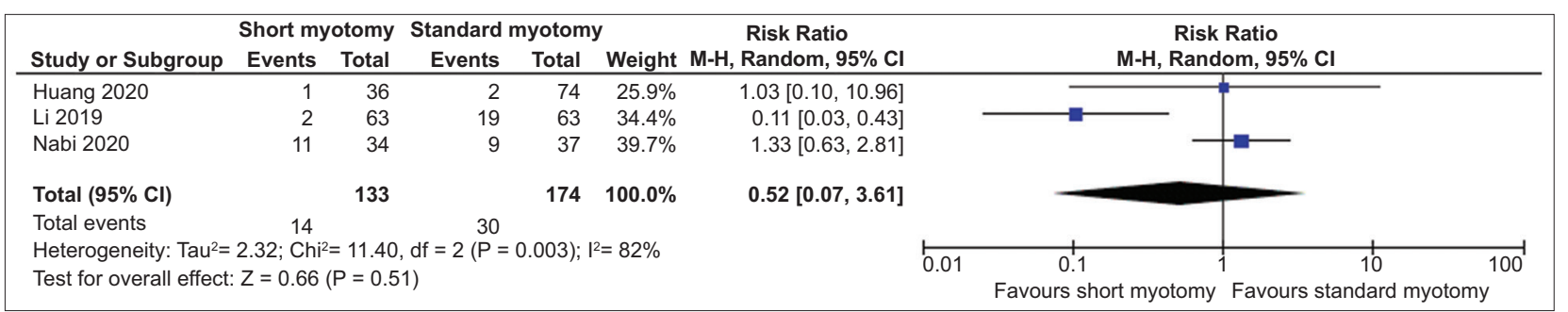

Supplementary Figure 2 Forest plot comparing short myotomy and standard myotomy regarding perioperative gas-related complications CI, confidence interval 


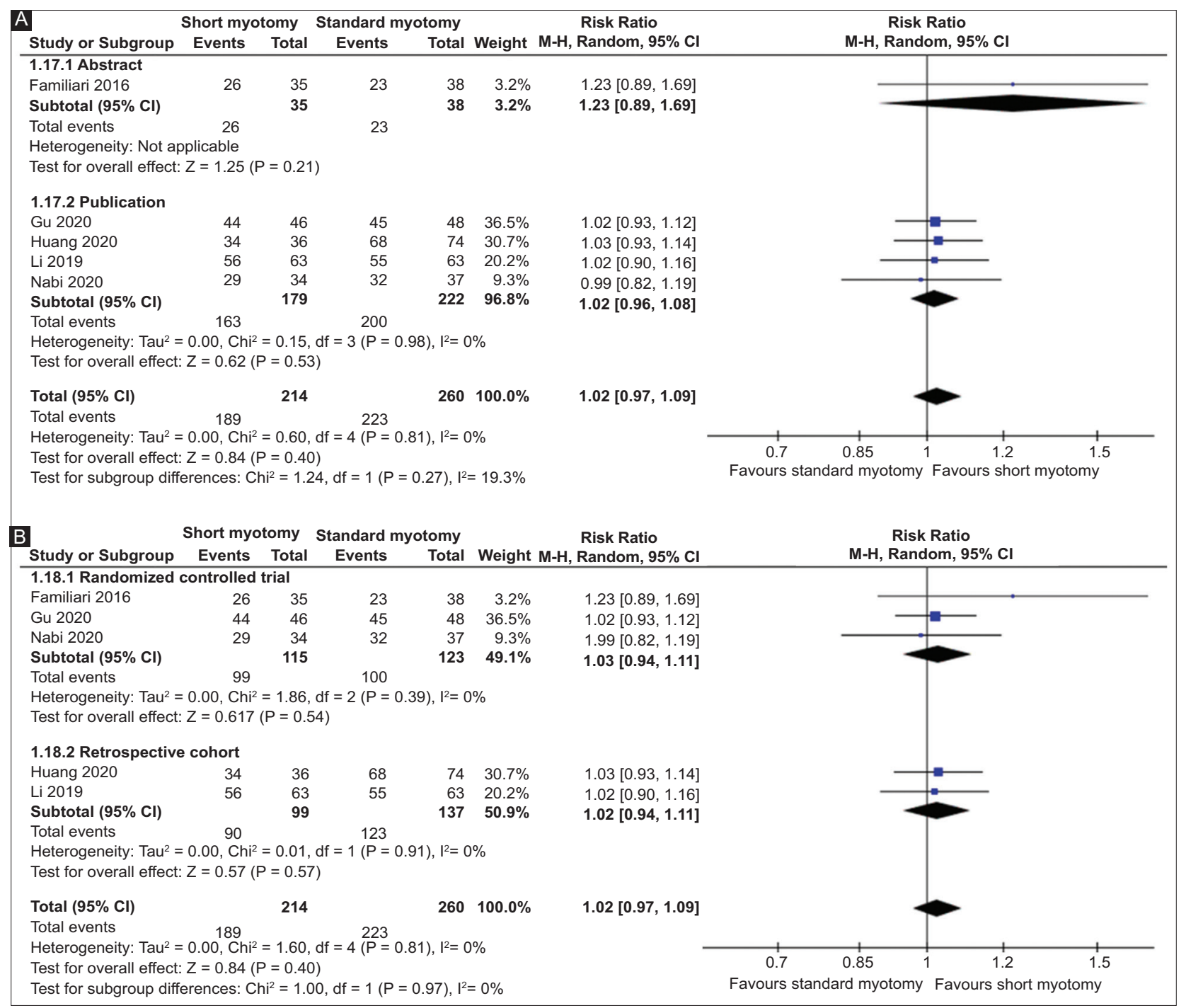

Supplementary Figure 3 Subgroup analysis comparing short myotomy and standard myotomy regarding clinical success rate based on (A) publication status and (B) study design

CI, confidence interval

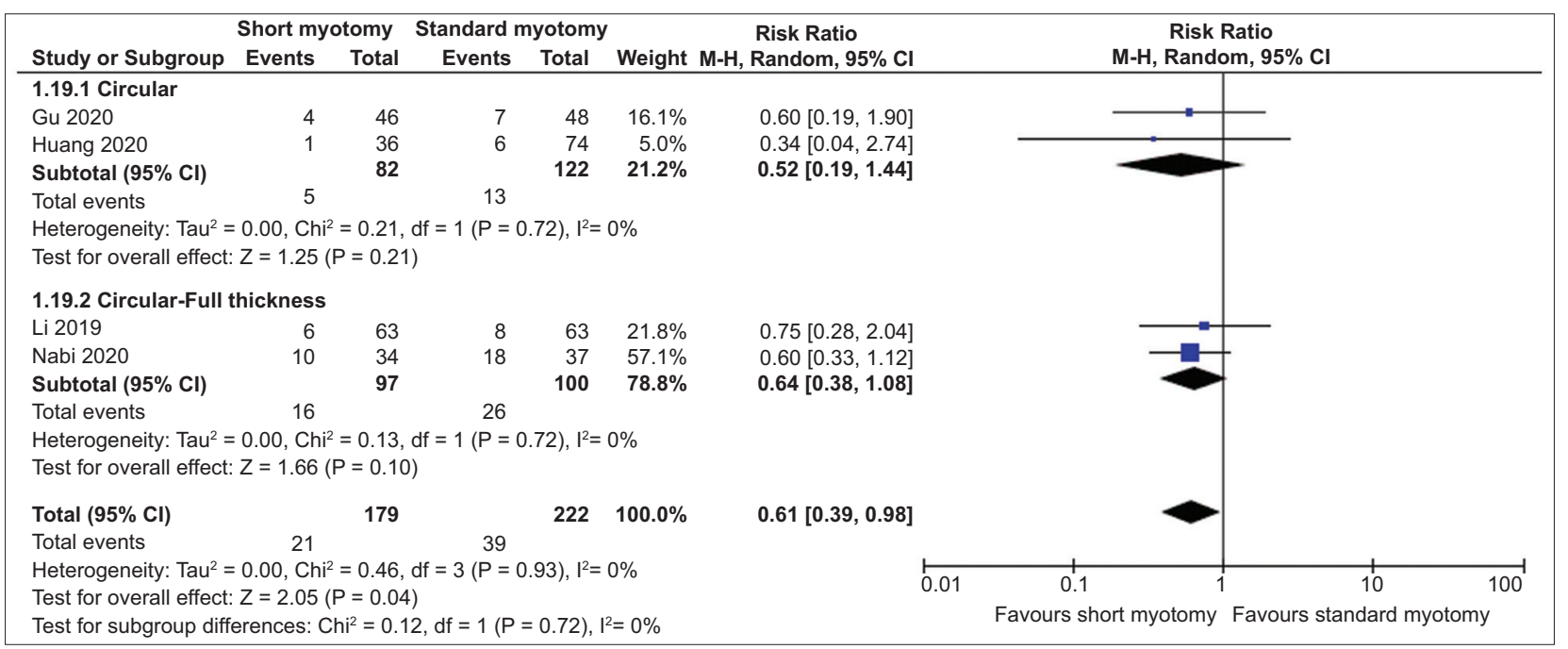

Supplementary Figure 4 Subgroup analysis comparing short myotomy and standard myotomy regarding reflux esophagitis based on depth of myotomy CI, confidence interval 


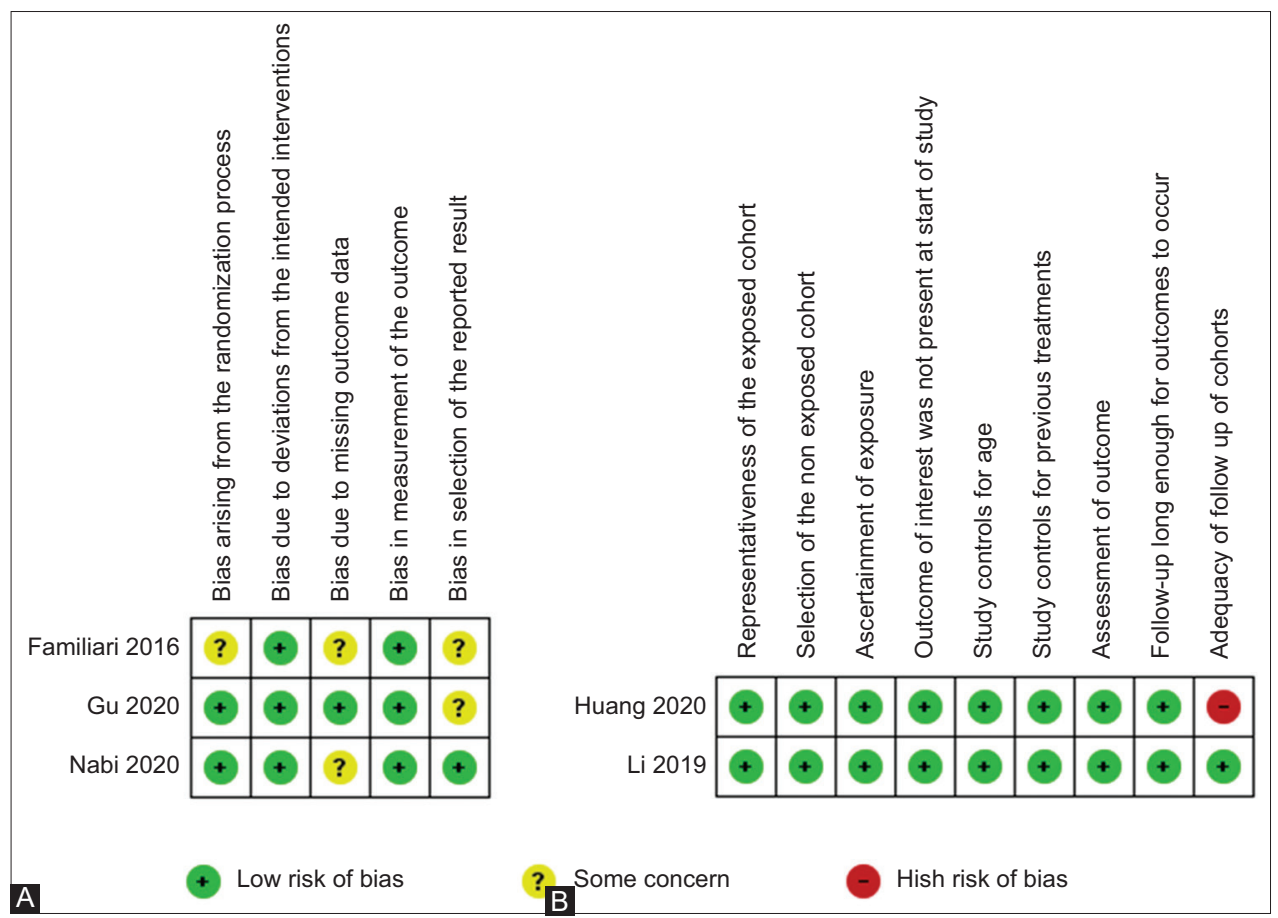

Supplementary Figure 5 Quality assessment of the included studies using (A) revised Cochrane risk of bias tool for randomized controlled trials and (B) Newcastle-Ottawa scale for cohort studies

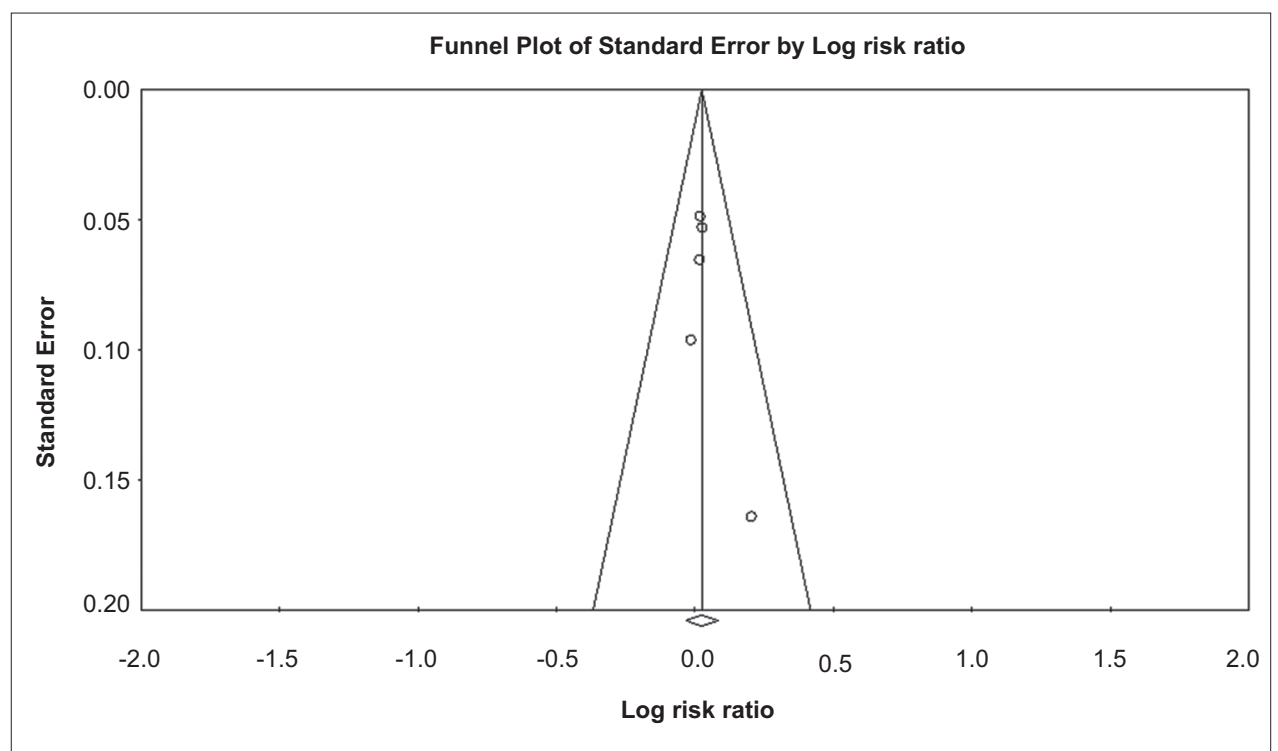

Supplementary Figure 6 Funnel plot showing publication bias analysis for clinical success rate

\section{Supplementary References}

1. Familiari P, Cali A, Landi R, et al. Long vs short POEM for the treatment of achalasia. Interim analysis of a randomized controlled trial. Dig Liver Dis 2016;48:e90.

2. Gu L, Ouyang Z, Lv L, Liang C, Zhu H, Liu D. Safety and efficacy of peroral endoscopic myotomy with standard myotomy versus short myotomy for treatment-naïve patients with type II achalasia: a prospective randomized trial. Gastrointest Endosc 2021;93:1304-1312.
3. Huang S, Ren Y, Peng W, et al. Peroral endoscopic shorter versus longer myotomy for the treatment of achalasia: a comparative retrospective study. Esophagus 2020;17:477-483.

4. Li L, Chai N, Linghu E, et al. Safety and efficacy of using a short tunnel versus a standard tunnel for peroral endoscopic myotomy for Ling type IIc and III achalasia: a retrospective study. Surg Endosc 2019;33:1394-1402.

5. Nabi Z, Ramchandani M, Sayyed M, et al. Comparison of short versus long esophageal myotomy in cases with idiopathic achalasia: a randomized control 